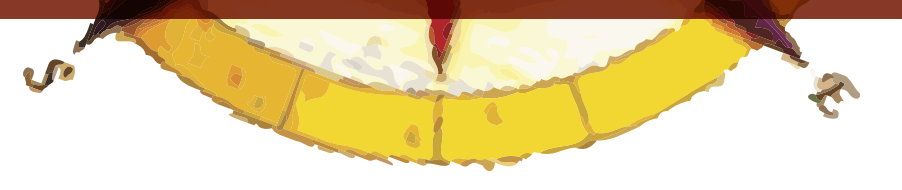

\title{
HISTÓRIA DE VIDA DE PROFESSORES DOS ANOS INICIAIS DO ENSINO FUNDAMENTAL E O ENSINO DE GEOGRAFIA
}

\author{
Antonio Carlos Pinheiro ${ }^{55}$
}

\section{RESUMEN}

El texto presenta informe de una investigación realizada con cuatro profesores, graduados en la Faculdad de Educación de la Universidad Federal de São Paulo - Guarulhos, que previamente cursou Magistério y actualmente trabajan en los primeiros años de educación primaria en la enseñanza de las escuelas publicas municipales de São Paulo, Guarulhos y Suzano. La metodología utilizada es autobiográfico. Se utilizó entrevistas con guión prévio y preguntas en acuerdo con la vida escolar, acadêmica y experiência profesional de los docentes con énfasis en la enseñanza de la Geografia. Los objetivos del estúdio son conocer por médio de las experiências formativas, el processo de alfabetización, la construcción de la identidad profesional y el contacto con la enseñanza de la Geografia; identificar a través de la autobiografia de los profesores, la trayectoria escolar como referencia para la comprensión de los procesos de socialización profesional; reflexionar sobre su práctica docente actual en particular la enseñanza de la Geografia en los primeros años de la escuela primaria.

Palabras-clave: Enseñanza de la Geografia - Autobiografia - Formación Profesional - Práctica Docente.

\section{RESUMO}

O texto apresenta o relato da pesquisa realizada com quatro professores concluintes do curso de Pedagogia na Faculdade de Educação da Universidade Federal de São Paulo - Guarulhos que cursaram anteriormente o Magistério e atualmente trabalham nos anos iniciais do ensino fundamental nas redes municipais de ensino de São Paulo, Guarulhos e Suzano. A metodologia utilizada é a autobiográfica. Foi usada entrevista com roteiro prévio e questões que tratam da trajetória escolar, acadêmica e experiência profissional dos professores, com destaque para o ensino de Geografia. Os objetivos do estudo são conhecer, com base em experiências formativas, o processo de alfabetização, a construção da identidade profissional e o contato com o ensino de Geografia; identificar, por meio da autobiografia dos professores, a trajetória escolar como referencia para entender os processos de socialização profissional; refletir sobre sua prática docente atual, em especial sobre o ensino de Geografia, nos anos iniciais do ensino fundamental.

Palavras-chave: Ensino de Geografia, Autobiografia, Formação Profissional, Prática docente. 


\begin{abstract}
The text reports research conducted by four teachers who were graduated in the School of Education at the Federal University of São Paulo - Guarulhos. These teachers, who have previously studied the so called Magisterium, currently work on the early years of primary education in municipal schools in São Paulo, Guarulhos and Suzano. The methodology used is autobiographical. The teachers were interviewed about their school trajectories, academic and professional experiences with emphasis on the teaching of Geography. The aims of the study are: to learn from the teachers' formative experiences, the process of literacy, the construction of professional identity and contact with the teaching of Geography; to understand through their autobiography, the professional socialization processes; to analyze their current teaching practices, in particular regarding the teaching of Geography during the early years of elementary school.
\end{abstract}

Keywords: Teaching Geography, Autobiography, Training, Teaching, Practice.

\title{
APRESENTAÇÃO
}

Este artigo apresenta aspectos da pesquisa realizada no Programa de Pós-doutorado da Faculdade de Educação da Universidade de São Paulo sob supervisão da Professora Doutora Sônia Maria Vanzela Castellar no ano de 2011. A investigação foi realizada com quatro professores que concluíram o curso de Pedagogia da Universidade Federal de São Paulo - campus Guarulhos - em 2010 e, anteriormente, cursaram o Magistério na modalidade do ensino médio. Há dez anos, todos os professores pesquisados atuam na escola básica dos anos iniciais do ensino fundamental nas redes públicas municipais de São Paulo, Guarulhos e Suzano.

$\mathrm{Na}$ pesquisa, as narrativas dos sujeitos foram estimuladas, orientadas e analisadas conforme os seguintes objetivos: conhecer com base em experiências formativas o processo de alfabetização, a construção da identidade profissional e o contato com o ensino de Geografia, o aprendido e o ensinado; identificar, por meio da autobiografia dos professores, a trajetória escolar como referência para entender os processos de socialização profissional; refletir sobre sua prática docente atual, em especial sobre o ensino de Geografia, nos anos iniciais do ensino fundamental.

O curso magistério na modalidade de ensino médio, também chamado de curso normal, durante muitos anos foi o responsável pela formação de professores para a educação infantil e para os anos iniciais do ensino fundamental. Com a promulgação em 1996 da Lei no 9394/96 (Lei de Diretrizes e Bases da Educação Nacional - LDB), é que se esta projetou uma formação para o ensino superior. No Título VI da LDB "Dos Profissionais da Educação”, o artigo 62, que trata da formação docente, descreve que:

A formação de docentes para atuar na educação básica far-se-á em nível superior, em curso de licenciatura, de graduação plena, em universidades e institutos superiores de educação, admitida, como formação mínima para o exercício do magistério na educação infantil e nas quatro primeiras séries do ensino fundamental, a oferecida em nível médio, na modalidade $\mathrm{Normal}^{56}$.

56 (BRASIL) Senado Nacional. LEI n ${ }^{\circ}$ 9.394, de 20 de dezembro de 1996, que estabelece as diretrizes e bases da educação nacional. Brasília, 1996. 
No entanto, a LDB considera que a formação mínima desejada para todos os professores seja a formação em nível superior. Mesmo admitindo a formação em nível médio, em muitos estados os governos passaram a desestimular e não mais oferecer, a partir de 2006, os cursos de formação de professores no ensino médio, os quais passaram a ser de responsabilidade do curso superior de Pedagogia. Em 15 de maio de 2006, o Conselho Nacional de Educação (CNE) promulgou a Resolução CNE/CP n ${ }^{\circ}$. 1, que institui as Diretrizes Curriculares Nacionais para a Licenciatura do curso de Pedagogia, estabelecendo no artigo $4^{\circ}$ que:

O curso de licenciatura em Pedagogia destina-se à formação de professores para exercer funções de magistério na Educação Infantil e nos anos iniciais do Ensino Fundamental, nos cursos de Ensino Médio, na modalidade Normal, de Educação Profissional, na área de serviços e apoio escolar e em outras áreas nas quais sejam previstos conhecimentos pedagógicos (CNE, 2006, p. 8) $)^{57}$.

Em 2007, os cursos de Pedagogia passaram por um processo de reformulação, a fim de atender a essa resolução, portanto, considera-se que as novas atribuições desse curso são recentes, e apenas no ano de 2010 é que começara a formar as primeiras turmas de professores para a educação infantil, para os anos iniciais do ensino fundamental e para a educação de jovens e adultos.

Neste artigo, apresento uma breve reflexão sobre as metodologias biográficas nas quais se inserem o gênero de história de vida, o perfil dos professores sujeitos da pesquisa, os procedimentos utilizados, um breve relato sobre a trajetória formativa dos professores, sua prática docente e como a Geografia se situa nos anos iniciais do ensino fundamental.

\section{METODOLOGIAS QUALITATIVAS BIOGRÁFICAS}

A História de vida, como metodologia de pesquisa, compõe, em conjunto com outras modalidades como a história oral, a biografia e a autobiografia, o gênero investigativo do quadro referencial das metodologias qualitativas biográficas. Cada um desses métodos, apesar de suas proximidades, contém procedimentos próprios. Embora não exista consenso entre os pesquisadores em seu uso, é possível destacar algumas singularidades. A história oral tem como finalidade entender e aprofundar conhecimentos sobre determinada realidade por meio de conversas com pessoas e relatos orais. $\mathrm{Na}$ biografia, podem-se utilizar diversas fontes com o objetivo de entender a história e o percurso de vida de uma pessoa, por meio de cartas, fotos, filmagens, documentos pessoais, depoimentos, entre outros recursos. A autobiografia se caracteriza pelo discurso voltado diretamente ao leitor. Constitui-se na narrativa das experiências pessoais articuladas à sequência temporal e ao contexto histórico, bem como na descrição de momentos da história do sujeito pesquisado (Silva et al., 2007). As metodologias biográficas A autobiografia estudam os laços objetivos entre o passado e o presente projetados ao futuro e considera as formas de subjetivação nas relações consigo mesmo e com outras instituições sociais. Os acontecimentos e a trajetória dos personagens podem revelar a conexão imaginária que os sujeitos mantêm com o presente, em tudo aquilo que acreditam, imaginam e projetam (Hernández, 2010).

A experiência de relatar sua história de vida oferece àquele que a conta uma oportunidade de reexperimentá-la, resignificando sua vida (Silva, et al., 2007, p. 31). Além disso, estabelece um vín-

57 (BRASIL) Conselho Nacional de Educação. Resolução CNE/CP nº. 1/2006. Brasília, 2006. <http://portal. mec.gov.br/cne/arquivos/pdf/rcp01_06.pdf>. Acesso em: 26 set. 2011. 
culo entre o pesquisador e o sujeito pesquisado. O sentido que o sujeito dá para sua história de vida desperta no pesquisador o repensar de sua própria experiência. A análise da narrativa está centrada na relação entre o sujeito e o pesquisador. O relato não corresponde necessariamente ao real; o que importa é o sentido que o sujeito dá a essa realidade (Silva et al., 2007). A experiência vivida pelos sujeitos no decorrer do tempo inclui uma seleção de sucessos, pessoas e situações em que cada um que participou e sua interpretação é mediada pelas experiências posteriores. Quem narra sua experiência o faz com base nas crenças, nos valores e nas atitudes do presente (Alliaud, 2010). Outro dado importante é o contexto histórico e social em que o sujeito produz seu relato. Além da escola, o momento sociohistórico dos sujeitos é significativo para explicar sua história de vida, assim como suas relações familiares, de classe social e de gênero.

Goodson (1995) defende que os dados sobre a vida dos professores é um fator importante para a investigação educacional, considerando essa prática como uma questão substantiva:

a razão primordial é que, segundo minha experiência, quando falo com professores sobre problemas de desenvolvimento curricular, matérias de ensino, gestão escolar e organização geral das escolas, eles trazem à colação, constantemente, dados sobre as suas próprias vidas. Isto pode ser tomado como prova razoável de que os próprios professores consideram estes problemas da maior relevância. Uma das razões por que estes dados não têm sido muito utilizados deve-se ao facto de os investigadores os rotularem de demasiado "pessoais", "idiossincráticos" ou "flexíveis"; constitui, em suma, mais um exemplo da utilização selectiva da "voz do professor". O investigador só escuta o que quer ouvir e sabe o que tem melhor aceitação por parte da comunidade científica [grifos do autor] (Goodson, 1995, p. 70).

Monteagudo (2010) apresenta a Autobiografia Educativa (ABE) como uma modalidade que vem crescendo entre os pesquisadores nos últimos anos. Para ele, a ABE possibilita explorar o passado e o presente do contexto familiar, da comunidade local, das relações institucionais e socioculturais mais amplos. Como instrumento de formação, favorece o autoconhecimento, a capacidade de análise do passado, o estabelecimento de relações entre a experiência vivida, o presente, os projetos de futuro e a identificação dos fatores mais importantes que condicionam a trajetória pessoal e educativa dos sujeitos pesquisados. A ABE pode contribuir na formação profissional na medida em que constitui um instrumento de análise e reflexão das aprendizagens realizadas ao longo da vida dos sujeitos, podendo explicitar seus modelos e paradigmas pessoais em relação ao conhecimento, suas representações, relações interpessoais e valores educativos. As narrativas podem ser individuais ou por seções em grupos, centradas na oralidade ou na escrita. Todos esses procedimentos podem promover uma apropriação da experiência, em que o próprio sujeito, autor do relato, pode converter-se em analisador do texto. A autobiografia permite uma aprendizagem baseada na experiência: "a objetivação do passado e dos eventos ocorridos se combina com a rememorização subjetiva da experiência que o sujeito reconfigura e se apropria durante o processo da reflexão" (Monteagudo, 2010, p. 80).

Falar da própria história de vida, das experiências vivenciadas e acumuladas é um processo reflexivo que leva o sujeito a repensar suas ações no presente e no passado. Rememorar fatos resiguinificando e reeditando-os por meio da narrativa, das experiências vividas e imaginadas, representa para sua identidade uma reconstrução e uma reinvenção por meio da memória, e sobre isso Ecléa Bosi (1994) explica:

$\mathrm{Na}$ maior parte das vezes, lembrar não é reviver, mas refazer, reconstruir, repensar, com imagens e ideias de hoje, as experiências do passado. A memória não é sonho, é trabalho. Se assim é, deve-se 
duvidar da sobrevivência do passado, "tal como foi", e que se daria no inconsciente de cada sujeito. A lembrança é uma imagem construída pelos materiais que estão, agora, à nossa disposição, no conjunto de representações que povoam nossa consciência atual. Por mais nítida que nos pareça a lembrança de um fato antigo, ela não é a mesma imagem que experimentamos na infância, porque nós não somos os mesmos de então e porque nossa percepção alterou-se e, com ela, nossas ideias, nossos juízos de realidade e de valor. O simples fato de lembrar o passado, no presente, exclui a identidade entre as imagens de um e de outro, e propõe a sua diferença em termos de ponto de vista (p. 55).

A identidade reconstruída no presente estabelece uma relação de exclusão e inclusão, ou seja, exclui-se pela recordação aquilo que não foi significativo ou que simplesmente não queremos lembrar e incluem-se fatos dando nova cor para enfatizá-lo como algo importante. De qualquer forma, escolhemos, mesmo que inconscientemente, o que queremos lembrar num processo seletivo e subjetivo. Como diz Bosi, pensar o passado no presente ocorre por referenciais atuais, o momento já foi vivido num tempo-espaço determinado e distante. Recordar é um exercício do aqui-agora. Essa evidência transparece nas falas dos professores entrevistados. Percebe-se que, quando contam suas histórias, fazem correlações com sua experiência atual. Quando falam de sua escolarização inicial estão olhando para o presente, para sua prática docente como referência para falar de sua experiência como aluno.

\section{PERFIL DOS PROFESSORES E PROCEDIMENTOS DA PESQUISA}

Dos quatro professores entrevistados, dois são homens e duas são mulheres, com idades entre 27 e 47 anos. Dois homens e uma mulher entre 27 e 30 anos e uma mulher com 47 anos. Todos têm cerca de 10 anos de profissão. Para facilitar a reflexão sobre suas falas, optou-se por nomes fictícios: Fábio, 27 anos, Júlia, 29 anos, Paulo, 30 anos, e Marina, 47 anos. Marina entrou na escola na década de 1970 e os outros na década de 1980. Todos cursaram o curso Magistério na modalidade de ensino médio, sendo três em escolas públicas e um em escola privada. Três cursaram o Magistério no período diurno e um no período noturno. Dois fizeram o Magistério no antigo CEFAM (Centro de Formação e Aperfeiçoamento do Magistério) ${ }^{58}$. Todos são egressos do curso de Pedagogia da Faculdade de Educação da Universidade Federal de São Paulo - campus Guarulhos - e são da primeira turma de instalação do curso, em 2007. Dos quatro, os dois homens nasceram na cidade de São Paulo e as mulheres, uma em Santo André e a outra, em Guarulhos. Quanto à origem socioeconômica, todos são provenientes da classe trabalhadora com perfil de classe média baixa, sendo que um professor viveu uma situação precária na infância. Dos quatro professores, dois trabalham nas redes municipais de São Paulo e em Suzano e dois apenas na rede municipal de Guarulhos. Anteriormente, dois deles trabalharam em Franco da Rocha, na grande São Paulo e em Assis e Marília no interior do estado. Dois professores já trabalharam também na rede particular. Atualmente, três trabalham na rede pública municipal e uma nas redes municipal e estadual.

Com base nos objetivos propostos para a pesquisa e definição dos professores e das temáticas, organizamos a entrevista semiestruturada com roteiro e questões que tratassem da trajetória esco-

58 O Cefam (Centro de Formação e Aperfeiçoamento do Magistério) foi um projeto de curso de Magistério na modalidade de ensino médio criado em 1992 pela Secretaria do Estado de Educação de São Paulo voltado para a formação de professores de $1^{a}$ a $4^{a}$ séries, hoje chamado de anos iniciais do ensino fundamental. $\mathrm{O}$ curso funcionava em período integral, com duração de quatro anos em vários municípios do estado de São Paulo. Para ingressar era necessário que candidato fizesse uma prova e uma entrevista. Os aprovados recebiam uma bolsa de estudos no valor de um salário mínimo. O CEFAM foi extinto e formou sua última turma no ano de 2005. 
lar, acadêmica e experiência profissional dos professores nos anos iniciais do ensino fundamental com destaque para o ensino de Geografia. As entrevistas foram individualizadas. Para início do diálogo, apresentei uma síntese dos objetivos da pesquisa e solicitei sua autorização para gravar os depoimentos. O roteiro serviu como base, mas não foi seguido na sequencia. Durante as entrevistas, outras questões surgiram conforme as respostas dos professores. Após a entrevista, a gravação foi transcrita, editada, textualizada e devolvida para os professores, solicitando que completassem, alterassem ou propusessem novas questões que considerassem relevantes. Com as entrevistas editadas, iniciou-se a etapa da interpretação e reflexão cotejando as falas dos professores. Cada professor concedeu uma entrevista, sendo que as duas primeiras tiveram três horas de duração e as outras, duas horas cada uma. A cada entrevista o roteiro foi alterado, ora incluindo alguma questão, ora eliminando outras.

Cada entrevistado reviveu suas lembranças de maneira distinta, portanto, no texto podem aparecer mais referências sobre uns e menos sobre outros, o que não significa menos importância aos relatos de uns em detrimento de outros, de modo que aqui tudo foi aproveitado. Porém, como as questões foram livres, seus depoimentos fluíram conforme se sentiram à vontade para falar. $\mathrm{O}$ texto foi organizado conforme suas falas, e com base nelas fui interpretando, analisando e enxertando comentários, tanto de experiências pessoais como de reflexões a partir das citações e leituras realizadas para pensar a trajetória e a experiência dos professores. Também em alguns momentos utilizei a própria fala do entrevistado para ilustrar o texto, reproduzindo suas expressões. Considero que os professores pesquisados são também autores e, nesse sentido, somos mediadores. O texto segue o tempo cronológico da trajetória dos professores, no entanto, essa lógica não é estática. Durante suas lembranças, seus comentários e suas reflexões, os entrevistados se remetem há outros tempos e espaços para explicar suas experiências.

Para Goodson (1995), as experiências de vida e o ambiente sociocultural dizem o que somos. Quando os professores, sujeitos da pesquisa, falaram de suas trajetórias e práticas na escola, percebi como minhas experiências como aluno, tempos atrás, e como professor na escola básica, depois como formador na universidade, se assemelham aos seus relatos. Parece que a escola, apesar de suas singularidades, reflete um padrão que atravessa gerações e lugares distintos. Contudo, as reflexões presentes neste texto devem ser localizadas num determinado tempo-espaço, da trajetória escolar, formativa e profissional de quatro professores, entrevistados no primeiro semestre de 2011 na cidade de Guarulhos e São Paulo.

\section{TRAJETÓRIA FORMATIVA DOS PROFESSORES}

Começamos o relato com a formação escolar dos professores nos anos iniciais. Todos os professores entrevistados disseram que os conteúdos dos anos iniciais do ensino fundamental centravam-se na Língua Portuguesa e na Matemática; os outros apareciam nas áreas de Estudos Sociais e de Ciências. Em ambas as matérias suas professoras aproveitavam as datas comemorativas para trabalhar conteúdos de História, Geografia e Ciências. Essa prática foi comum para todos os professores sujeitos da pesquisa. Esse procedimento está bastante arraigado na cultura escolar, que aparece desde a década de 1970, quando Marina estudou nos anos iniciais, até a década de 1990 com Paulo, Fábio e Júlia. Sabemos que até hoje as datas comemorativas fazem parte da prática dos professores dos anos iniciais. Bergamaschi (2011) ao refletir sobre o ensino de História destaca que o que tem sido oferecido nas escolas como conhecimento histórico para os anos iniciais é a prática recorrente de datas comemorativas em que o professor 
assume uma perspectiva que se resume em festejar datas num desfile linear, anacrônico e sem significado, ao lembrar fatos do passado de forma descontextualizada e sob um único viés, decorrente da atuação épica de personagens, reverenciados como "heróis", e que figuram como seres sobrenaturais. É a escola contribuindo para canonizar uma verdade, naturalizar uma narrativa, onde não cabe a multiplicidade e nem tampouco a vida das pessoas que a estudam (p. 1-2).

Como a autora, afirmamos que, em Geografia, observamos o mesmo modelo. Marina relatou que não se lembra de uma matéria de que mais gostava; para ela, praticamente era tudo a mesma coisa. Em Estudos Sociais, por exemplo, a professora solicitava que os alunos lessem um parágrafo do livro e depois comentava a data. Marina lembra que, com esses conteúdos, fazia e coloria desenhos mimeografados ou carimbados no caderno pela professora.

De certa forma, todos os professores entrevistados lembram mais das brincadeiras do que dos conteúdos das matérias. Marina relatou que das coisas que ficaram dos anos iniciais, se recorda mais dos brinquedos e das brincadeiras com outras crianças, da professora que tocava violão e cantava e dos momentos do recreio.

Conversando com Marina, Paulo, Fábio e Júlia, constatamos que nos quatro anos da segunda etapa do ensino fundamental tivemos muitas matérias, muitos professores e muitos conteúdos. Perguntei se lembravam como aprenderam. As respostas foram diversas. Marina disse: "Quando se está na escola as pessoas estão envolvidas e vão aprendendo mesmo sem ter muita consciência e os conteúdos vão se incorporando". Na conversa com Fábio, citei a entrevista com Marina, que considera que não se lembra, mas que aprendeu e que os conteúdos foram internalizados. Perguntei se concordava. Respondeu que acha que não aprendeu mesmo e que nem deve estar gravado no seu inconsciente. Quando fez a prova para entrar na universidade, não se lembrou desses conteúdos. Para ele, o que mais marcou foram os amigos que conhece até hoje, as festas das quais participava e que ajudava a organizar.

\section{PRÁTICA DOCENTE DOS PROFESSORES}

Quando ingressou na docência, a maior preocupação de Marina era garantir que os alunos aprendessem os conteúdos trabalhados em sala de aula, fazer com que quando chegassem em casa falassem que ela passou várias atividades. Como no início trabalhava com crianças pequenas, era importante que elas levassem para casa, além das lições, hábito de higiene, por exemplo. No início da carreira, Marina pedia ajuda para os colegas mais experientes, buscava informações em livros e consultava as atividades dos professores mais antigos.

Paulo começou na educação infantil e sua maior preocupação era com a disciplina. Conseguir prender a atenção dos alunos, fazer com que eles o escutassem. Quando chegou à escola, ouvia os professores dizerem: "a educação está horrível, os alunos não respeitam, só falta o aluno bater no professor". Esse comentário o deixava muito preocupado. Mas com o tempo aprendeu a administrar a turma.

Fábio disse que teve ajuda das próprias crianças. Quando percebia que elas não entediam, mudava a forma de trabalhar. Considera que os alunos dão alguns indícios para o professor buscar novas metodologias. Também se apoiava nos fundamentos teóricos das disciplinas que estava cursando na Pedagogia. Diferente de Paulo, Fábio iniciou sua carreira na $2^{\circ}$ ano do ensino fundamental, mas 
disse preferir a educação infantil, primeiro porque é mais livre para trabalhar e segundo porque não teve bons professores especialistas na sua formação básica. Para ele, a educação infantil é mais contextual, não necessita de um conteúdo prévio para depois explicar, pois nessa modalidade pode ensinar a partir das coisas: "Da massinha que os alunos fazem, do espaço do parque que tem na escola". Como as atividades são mais práticas, permite que se trabalhe de forma mais livre e do seu modo. Para Fábio, apesar da vontade de desenvolver atividades diferentes, a dinâmica do ensino fundamental está cristalizada numa cultura escolar baseada em conteúdos e métodos rígidos, além de esbarrar em fatores que não permitem um trabalho livre com os alunos: "A estrutura da escola, a rotina desestruturada das coisas que vêm de fora, as provinhas e os livros didáticos limitam nosso trabalho".

Júlia se preocupava com tudo, tinha medo de não saber lidar com as crianças, com os pais, com a matéria. Começou sua carreira na escola privada e no início ficou assustada com medo de não conseguir trabalhar com a quantidade de conteúdos previstos para um único dia: "Tinha livros, apostilas, cadernos de todas as matérias e era muito cobrado o registro. Tinha que registrar várias coisas durante o dia, tinha medo de não dar conta de tudo aquilo". Quando entrou na escola pública encontrou o mesmo padrão baseado na quantidade e na produtividade. Descontente, resolveu se aproximar de uma professora que lhe mostrou outro caminho; aos poucos foi se desvencilhando daquele modelo e construindo o seu. "Hoje divido o tempo para brincar, para interagir, conversar, o tempo das atividades, da apresentação dos conteúdos, mas sem forçar que registrem tudo como a principal fonte de informação e aprendizagem."

Para Júlia, a distância de sua formação inicial com a realidade encontrada nas escolas foi um dos maiores problemas; muito pouco do que aprendeu no Magistério utilizou na prática. Perguntei se o curso de Pedagogia mudou sua prática docente. Disse que aprendeu muitas coisas importantes, mas ainda não consegue transformar em práticas para a sala de aula e para mudar a escola: "Não consigo convencer o grupo que algo é importante e nem colocar em prática, porque se fizer sozinha, todo mundo cai em cima de mim, fazer diferente dos outros vira uma guerra dentro da escola". Júlia revelou que tem conseguido desenvolver práticas não convencionais porque tem uma parceira na escola. Juntas, têm mais força para discutir e pensar em novas atividades.

Para Tardif (2010), os saberes dos professores são diversos: "é plural, compósito, heterogêneo, porque envolvem, no próprio exercício do trabalho, conhecimentos e um saber-fazer diverso, provenientes de fontes variadas e de natureza diferente" (p. 18). Nesse sentido, constituem uma somatória de saberes da formação profissional e de saberes disciplinares, curriculares e experienciais. Os professores entrevistados quando iniciaram na docência encontraram-se diante de uma realidade concreta e tiveram que buscar diversas formas de apoio para lidar com seus problemas. Cada um a seu modo, foram construindo a prática na interação com a escola real e com outros professores, experimentando por meio de erros e acertos. Os saberes experienciais constituem um

conjunto de saberes atualizados, adquiridos e necessários no âmbito da prática da profissão - formam um conjunto de representações a partir das quais os professores interpretam, compreendem e orientam sua profissão e sua prática cotidiana em todas as suas dimensões (Tardif, 2010, p. 49).

A identidade profissional constrói-se com base na significação social da profissão, na revisão dos seus significados, nas tradições, nos valores individuais dos professores, na história de vida, nas relações com outros professores, escolas, instituições, entre outros aspectos. A profissão do professor é uma prática social (Pimenta, 1997) e um processo de socialização (Tardif, 2010), portanto, não 
é um dado imutável nem externo que possa ser adquirido (Nóvoa, 1995), mas é um processo de construção do sujeito historicamente situado (Pimenta, 1997).

Sobre a experiência com a alfabetização, Marina afirmou que sua escola está voltada para as áreas de Língua Portuguesa e Matemática. Disse que a maioria dos professores trabalha dessa forma: "Na prática escolar existe grande valorização para essas duas áreas". Também falou da pressão existente por parte da direção e da coordenação da escola: "A criança tem que sair daqui lendo!". Revela que poderia dar um trabalho de Geografia envolvendo outras áreas como a leitura, mas a cobrança é muito forte em torno dos métodos de alfabetização baseados na língua portuguesa, principalmente para preparar os alunos para a "Provinha Brasil" 59 . Marina revelou que na sua escola fazia simulado da Provinha Brasil para as crianças se acostumarem com a prova. Essas avaliações que já aparecem nos anos iniciais, nos $2^{\circ}$ e $5^{\circ}$ anos, acabam direcionando o ensino para que os alunos tenham bom desempenho nas áreas que a prova pretende avaliar. Na Provinha Brasil, realizada no $2^{\circ}$ ano, o foco é a alfabetização baseada na Língua Portuguesa. A prova realizada no $5^{\circ}$ ano avalia o desempenho dos alunos na Língua Portuguesa e na Matemática. Marina revelou que isso reflete na organização das aulas. Dos cinco dias da semana, nos $1^{\circ}$ e $2^{\circ}$ anos, basicamente todos os dias são dedicados para a alfabetização na área de Língua Portuguesa. Do $3^{\circ}$ até o $5^{\circ}$ ano, três dias para Português, um dia para Matemática e um dia para o restante: História, Geografia, Ciências, Artes e atividades físicas. A partir de 2011, a Provinha Brasil começa avaliar também Matemática no $2^{\circ}$ ano e Ciências no $5^{\circ}$ ano, portanto, segundo ela, a escola deverá organizar a semana entre essas disciplinas.

A Provinha Brasil tem sua importância, porém, como acabam avaliando por meio dos alunos, o desempenho dos professores, dos gestores e da escola, muitos profissionais direcionam seu trabalho para que os alunos tenham bons resultados. Sabe-se que muitos municípios utilizam os índices de aprovação e desempenho para gratificar financeiramente os professores e gestores, tornando a Provinha um instrumento de controle do currículo escolar. Por vezes, os recursos financeiros destinados à unidade escolar estão atrelados aos resultados dessas provas. Uma prática perversa de controle e uso da avaliação institucional.

59 A Provinha Brasil é uma avaliação diagnóstica aplicada aos alunos matriculados no segundo ano do ensino fundamental. A intenção é oferecer aos professores e gestores escolares um instrumento que permita acompanhar, avaliar e melhorar a qualidade da alfabetização e do letramento inicial oferecidos às crianças. Com base nas informações obtidas pela avaliação, os professores têm condições de verificar as habilidades e deficiências dos estudantes e interferir positivamente no processo de alfabetização, para que todas as crianças saibam ler e escrever até os oito anos de idade, uma das metas do Plano de Desenvolvimento da Educação (PDE). $<<$ http://portal.mec.gov.br/index.php?option=com_content\&view=article\&id=211\&Itemid=328>. Acesso em: 8 ago. 2011. Também existem a Prova Brasil e o Sistema Nacional de Avaliação da Educação Básica (Saeb), que, segundo o Ministério da Educação: "São avaliações para diagnóstico, em larga escala, desenvolvidas pelo Instituto Nacional de Estudos e Pesquisas Educacionais Anísio Teixeira (Inep/MEC). Têm o objetivo de avaliar a qualidade do ensino oferecido pelo sistema educacional brasileiro a partir de testes padronizados e questionários socioeconômicos. As provas são aplicadas na quarta e oitava séries (quinto e nono anos) do ensino fundamental e no terceiro ano do ensino médio. Os estudantes respondem a itens (questões) de Língua Portuguesa, com foco em leitura, e Matemática, com foco na resolução de problemas. No questionário socioeconômico, os estudantes fornecem informações sobre fatores de contexto que podem estar associados ao desempenho. Professores e diretores das turmas e escolas avaliadas também respondem a questionários que coletam dados demográficos, perfil profissional e de condições de trabalho. A partir das informações do Saeb e da Prova Brasil, o MEC e as secretarias estaduais e municipais de Educação podem definir ações voltadas ao aprimoramento da qualidade da educação no país e a redução das desigualdades existentes, promovendo, por exemplo, a correção de distorções e debilidades identificadas e direcionando seus recursos técnicos e financeiros para áreas identificadas como prioritárias." $<$ http://portal.mec.gov.br/index.php?option=com_content\&view=article\&id=210\&Itemid=324>. Acesso em: 8 ago. 2011. 


\section{O ENSINO DE GEOGRAFIA NOS ANOS INICIAIS}

Conversando com Marina, lembrei que disse que existem poucas aulas de Geografia, sobretudo pela importância dada tradicionalmente à área da Língua Portuguesa e da Matemática nos anos iniciais, principalmente pela influência da Provinha Brasil, que direciona a alfabetização para essas áreas. Perguntei o que considera importante para os alunos aprenderem nessa etapa da escolarização, em Geografia, e qual a contribuição dessa área na formação das crianças. Para Marina, a contribuição está relacionada com a noção de espaço. Na escola com as crianças, acredita que o mais imediato é começar pela localização da sala de aula. Segundo ela, as crianças entram na sala errada, trocam de banheiro, os meninos entram no banheiro das meninas e vice-versa:

no dia a dia pede-se para o aluno sentar num lugar e ele não entende o comando. $\mathrm{O}$ aluno precisa entender qual é o lugar dele no mundo. A escola é diferente da casa. As crianças têm que perceber essas diferenças. Independente da forma da família, ele deve saber que tem vizinhos, amigos. Na escola os banheiros são divididos, mas na casa não é. Outra forma de trabalhar o espaço é a fila. Quando o professor fala para fazer a fila, muitos alunos não sabem para onde ir, todo dia tem que organizar. A tendência é todos ficarem juntos no mesmo lugar, daí falo: vai mais para trás, tem mais lugar, vai lá do outro lado... (Marina).

Sobre a divisão entre meninos e meninas, Marina foi questionada por que eles têm que aprender desde cedo seu lugar. Para ela, é uma questão social, uma vez que a fila é feita quase que "naturalmente" há muito tempo na escola, e sua divisão não tem a intenção de separar os gêneros; é uma prática da escola e os professores a fazem desde sempre.

Para Paulo, a dificuldade para trabalhar com outras áreas nos anos iniciais está relacionada com a alfabetização:

na Geografia e na Matemática dá para fazer uma atividade de alfabetização no primeiro e no segundo ano com noções básicas e conceitos amplos. Porém, a criança tem que saber escrever e ainda está no nível pré-silábico, daí não consigo ensinar Geografia e História sem uma reflexão por escrito. Dá para ensinar ler um mapa, mas pedir para eles localizarem uma rua é difícil: o MASP está em qual rua? Se os alunos não sabem ler a palavra "MASP" (Museu de Arte de São Paulo) e se tiver que ensinar a palavra e o nome da rua, trata-se de uma atividade de alfabetização. Quero que eles procurem, que leiam, mas se não sabem ler, então não dá pra fazer (Paulo).

Paulo afirma que os conteúdos de Geografia têm um caráter diferenciado nos dois primeiros anos em relação ao terceiro, quarto e quinto anos. Para ele, nos três últimos anos, os alunos têm condições de opinar sobre os conteúdos. Os alunos dos dois primeiros anos não têm reflexão para entender as questões econômicas. Segundo sua experiência, ele afirma que nos três últimos anos o aluno tem noção de que o "pai não vai comprar a bicicleta porque não tem dinheiro". Com isso, prefere trabalhar conteúdos de Geografia nos três anos finais. Para muitos professores, a alfabetização está relacionada com as atividades de leitura e escrita, que, por sua vez, ocorre pelo domínio das palavras e das regras gramaticais da língua. Acreditam que não seja possível trabalhar com conteúdos de outras matérias se os alunos não sabem ler e escrever palavras. Por isso primeiro alfabetiza e depois trabalham com outras áreas do conhecimento.

O que Júlia conseguiu trabalhar com os alunos na área de História e Geografia foi relacionar a identidade deles com a família, como origem e moradia: "Como a maioria era da região Nordeste, mostrei onde ficava a região no mapa". Também conversou sobre a planta baixa da casa, primeiro 
produzindo uma planta da escola e depois da casa deles, mas disse que seu trabalho foi bem superficial, logo tendo que parar para dar continuidade à alfabetização.

Para Fábio, a Geografia pode contribuir para a compreensão do mundo, do tempo, do espaço, da política, que também é papel da História. Para ele, a atribuição dessas duas disciplinas é:

compreender o mundo, o espaço que as pessoas vivem, as relações de tempo, as dinâmicas sociais de crescimento demográfico, a própria história do aluno. Fenômenos que resultaram para ele estar ali, não biológicos porque são mais fáceis de entender, mas fenômenos sociais. Como é no meu caso. Moro em São Miguel Paulista, onde tem muitos migrantes nordestinos que foram para São Paulo e vivem nesse bairro. Como é a história dos meus pais (Fábio).

Perguntei para Júlia qual era a importância e a contribuição da Geografia para os anos iniciais. Ela disse que é importante para os alunos conhecerem, não só fisicamente, mas a realidade social da região que moram, a cidade, o país. Conhecer a realidade para ela significa entender a cultura, a sociedade em que se vive. Para ela, é imprescindível discutir por que acontecem determinados fatos e fenômenos, o que é a política e o que é viver em sociedade: "Falo muito para as mães que eles vêm para a escola para aprender a viver em sociedade e viver em sociedade não é fácil, é reprimir aquilo que a gente gostaria de fazer, para que outros possam ter benefícios". Para ela, viver em sociedade é saber dividir, saber diferenciar um fato do outro: "Até onde posso chegar, até onde posso ir". Na educação infantil e nos anos iniciais do ensino fundamental, segundo Júlia, é importante situar a criança na sociedade e ensinar o que significa viver nessa sociedade.

Apesar do reconhecimento dos professores do valor da Geografia para os anos iniciais, identifiquei pouca inserção da matéria no currículo. Como conteúdo, a Geografia não tem uma regularida$\mathrm{de}, \mathrm{e}$, assim como em outras áreas, ela aparece pontualmente podendo estar relacionada às "datas comemorativas" ou articulada a algum tema da atualidade, como, por exemplo, "Copa do Mundo de Futebol".

Com base nos depoimentos dos professores, nota-se que a concepção de alfabetização está atrelada à área de Língua Portuguesa e seus métodos, assim como a concepção de leitura e de linguagem está restrita à escrita. Ler e escrever têm sido tradicionalmente atributos da língua escrita e, mesmo com os avanços das várias áreas do conhecimento para os anos iniciais, tal visão predomina na prática docente dos professores. Evidente que se faz necessário que os alunos se apropriem dos códigos e das regras para ler e escrever. Porém, a língua escrita não é necessariamente a que as pessoas se expressam no cotidiano. $\mathrm{Na}$ fala existem muitas expressões que nem sempre são possíveis de serem reproduzidas pela norma culta, uma que elas refletem sotaques, regionalidades, localidades que são legítimas, visto que suas falas são reconhecidas e praticadas por um conjunto de pessoas. Assim, estabelecer um diálogo entre a língua falada e a ensinada na sala de aula implica considerar as relações com os lugares e sua gente.

$\mathrm{Na}$ escola a língua é central no processo de ensino-aprendizagem dos alunos. Essa forte tradição escolar centraliza todo o currículo para aprendizagem da língua escrita, tornando-a essencial para a aprendizagem de outros conteúdos provenientes de outras áreas. Essa tendência não está apenas na escola, mas ultrapassa seus muros envolvendo os gestores e técnicos das redes de ensino e a própria sociedade que a valoriza como a razão de ser da escola, especialmente dos anos iniciais. Em segundo lugar, aparece a Matemática, expressa no domínio das operações básicas. Mesmo com novas teorias de aprendizagens, novos métodos, novos problemas do mundo atual, grande parte 
das escolas, principalmente as voltadas para as classes trabalhadoras, continuam centralizando sua tarefa em ler-escrever-contar.

Entendemos que o processo de aprendizagem deve libertar a leitura da escrita. Ler é produzir sentido, é se envolver com o objeto de leitura (Guedes e Souza 1999). Esse processo não se dá apenas por palavras, embora estas sejam o código que garante seu registro. Na Geografia, por exemplo, as crianças podem ler o lugar de vivência e sua paisagem e expressá-los por meio de outras linguagens alternativas, como desenhos, relatos, cinema, música, literatura, dramatização, charges, internet, jogos virtuais e computador (Cavalcanti, 2010). Com isso é possível articular o processo de alfabetização da palavra escrita com os sentidos do mundo em que essa criança vive. Compreender o significado social da palavra pode potencializar a compreensão do mundo e, nesse sentido, a Geografia tem uma contribuição no processo de alfabetização:

quando se lê a palavra, lendo o mundo, está-se lendo o espaço... [ ] [ ]... a leitura do espaço permite que se faça o aprender da leitura da palavra, aprendendo a ler o mundo. A partir daí a Geografia pode trabalhar com os conceitos que são próprios do seu conteúdo (Callai, 2005, p. 233).

Nesse sentido, como em outras áreas do conhecimento, na Geografia os professores abordam os conteúdos relacionando-os com suas experiências de vida, porém é importante que eles percebam que as dimensões espaciais e temporais são mais do que meros conteúdos pontuais, mas são conceitos que permeiam o processo de escolarização das crianças desde o $1^{\circ}$ ano até o $9^{\circ}$ ano do ensino fundamental. O espaço geográfico compõe uma complexidade e sua extensão, como afirma Cavalcanti (2010), exige compreendê-lo amplamente, considerando que

a espacialidade, produto e condição de práticas sociais, é compreendida, no mundo contemporâneo, como uma realidade complexa, que expressa práticas fragmentadas, desiguais, diferenciadas, multiculturais, interculturais, desterritorializadas/reterritorializadas, organizadas em fluxos e redes, midiáticas e informatizadas. (p. 371-372).

A questão dos saberes não é meramente uma questão epistemológica, metodológica, didático-pedagógica, mas uma questão política-cultural:

os saberes são elementos constitutivos da prática docente, logo não são lineares e fixos. O saber é formado por diversos fatores, envolvendo o conhecimento científico, disciplinar, da formação básica e profissional e de saberes experienciais que o próprio sujeito adquiriu na sua vida em determinados tempos e espaços (Fonseca.; Borges; Silva Jr., 2007, p. 35).

Fonseca, Borges e Silva Jr. (2007) afirmam que no Brasil o lócus do conhecimento científico, no campo da História e da Geografia, é a universidade. A difusão dos conhecimentos está sob o poder da comunidade acadêmica que influencia na formulação dos saberes curriculares. A definição do que é ensinável nos campos disciplinares e podem ser didatizados nem sempre é atribuição dos professores da escola básica. Porém, na sala de aula quem organiza e aborda esses conhecimentos são esses professores que os fazem com seus saberes.

Destaca-se que, entre a produção primária do conhecimento, ou seja, a pesquisa inicial realizada na academia e sua transformação em conteúdos de ensino para a educação básica existe um longo caminho. $\mathrm{O}$ produto da pesquisa inicial pode se transformar em artigos científicos para sua divulgação, podendo em conjunto com outros textos se constituírem em manuais didáticos de cursos superiores ou de textos dirigidos aos professores da educação básica. Além disso, nesse caminho, 
muitas temáticas da Geografia podem passar pelas mídias destinadas ao público não escolar e muitas vezes ser utilizadas pelos professores como recurso didático, além dos conteúdos dos livros didáticos destinados aos alunos da escola básica. E na ponta de todo esse processo estão os alunos que se apropriam desse conhecimento transformando-os em saberes, os quais ocorrem numa trama complexa de compreensão e de interesses pessoais.

\section{CONSIDERAÇÕES FINAIS}

Acredita-se que a vivência, a experiência e a prática docente constituem o cerne das análises desta pesquisa. Os professores expuseram suas vidas, seus saberes, suas experiências e, em decorrência, pude conhecê-los mais e acredito que esse diálogo contribuiu para repensar sobre minha própria prática na universidade como formador de professores e sobre o papel da Geografia nos anos iniciais do ensino fundamental. Os professores foram considerados autores das suas vidas e das suas práticas. Suas falas foram consideradas como conhecimento construído nas adversidades da carreira e do cotidiano escolar. Conhecer a trajetória escolar dos professores e sua história de vida constitui a chave para entender os processos de socialização profissional que acontecem nas escolas. É na formação em serviço e na vivência escolar que o professor internaliza modelos de ensino, saberes e regras, além de comportamentos que resultam em práticas docentes, sobretudo nos primeiros anos de trabalho.

O relato da trajetória formativa dos professores apresenta uma característica comum que aparece na prática docente de todos eles: a pouca inserção do ensino de Geografia nos anos iniciais e a permanência das "datas comemorativas" como sinônimas de ensino dessa matéria, assim como ocorre com História e Ciências, o que não garante o ensino dessas áreas. Esse modelo aparece desde a década de 1970 e 1980 nos relatos da formação escolar dos professores e, posteriormente, em suas práticas docentes atuais. É um procedimento que existe há muito tempo nas escolas.

A concepção de alfabetização permanece atrelada ao ensino da língua. A leitura e escrita estão articulada às palavras e às regras gramaticais. Embora existam outras atividades, como desenhos, brincadeiras, estas são realizadas para outros fins que não o ensino dos conteúdos das matérias. Tanto o ensino da língua, da Matemática como de outras áreas ocorrem por meio da memorização e da repetição de exercícios de fixação e estão direcionados para obtenção de bons resultados conforme as exigências das avaliações institucionais. Todos os esforços das escolas parecem voltados para o melhor desempenho nas provas, principalmente porque é por meio delas, na atualidade, que a escola, os gestores e os professores aumentam seus recursos financeiros.

As dificuldades dos professores entrevistados para trabalhar com a Geografia e outros componentes curriculares se relacionam com o ensino que tiveram na sua formação básica escolar. Nesse sentido, as disciplinas específicas de metodologias nos cursos de formação inicial são insuficientes. Com exceção da língua e da Matemática, todas as outras disciplinas são dadas em um semestre, impossibilitando o aprofundamento dos conteúdos específicos de cada área. Os professores atribuem as dificuldades para trabalhar com esses conteúdos, nos anos iniciais, à sua formação escolar. Diante disso, considera-se que é preciso repensar o ensino, em especial o de Geografia, em todas as modalidades, desde o ensino fundamental, passando pelo ensino médio, até a universidade. Também é fundamental repensar os cursos de licenciatura de Geografia que darão o embasamento para que os professores e outros profissionais compreendam sua importância como instrumento para entender o mundo. Os professores especialistas em Geografia na escola básica, por meio da prática de um 
ensino significativo, são essenciais na formação dos professores dos anos iniciais e para a inserção dessa área na formação de todos os sujeitos na sociedade. Para terminar, é desejável que as tradicionais barreiras entre os professores especialistas de Geografia, os professores da educação infantil e os dos anos iniciais sejam rompidas, pois hoje todos passam pelo ensino superior, de modo que não há mais sentido diferenciá-los pela sua formação profissional. Diante disso, se faz necessário, entre os pesquisadores das didáticas especificas, dos professores das metodologias, das licenciaturas, estabelecerem um diálogo para que, em comum, possam identificar os problemas e as dificuldades da escola básica desde a educação infantil até o ensino superior.

\section{BIBLIOGRAFIA}

Alliaud, A. La biografia escolar de los docentes. Modos de abordage y perspectivas de formación. In: Moraes, D. Z.; Lugli, R. S. G. (Orgs.). (2011). Docência, pesquisa e aprendizagem: (auto) biografias como espaços de formação/investigação. São Paulo: Cultura Acadêmica, p. 37-51.

Bergamaschi, M. A. O tempo histórico nas primeiras séries do ensino fundamental. <http://168.96.200.17/ar/libros/anped/1317T.PDF>. Acesso em: 15 ago. 2011.

Bosi, E. (1994). Memória e sociedade: lembranças de velhos. São Paulo: Companhia das Letras.

(Brasil) Senado Nacional. Lei ${ }^{\circ}$ 9.394, de 20 de dezembro de 1996 que estabelece as diretrizes e bases da educação nacional. Brasília, 1996. <http://www6.senado.gov.br/legislacao/ListaTextoIntegral.action?id=75723>. Acesso em: 26 set. 2011.

(Brasil) Conselho Nacional de Educação. Resolução CNE/CP n ${ }^{\circ}$ 1/2006. Brasília, 2006. <http:// portal.mec.gov.br/cne/arquivos/pdf/rcp01_06.pdf>. Acesso em: 26 set. 2011.

Callai, H. C. (2005). Aprendendo a ler o mundo: a Geografia nos anos iniciais do ensino fundamental. Cadernos Cedes (66). São Paulo: Cortez, Campinas: Cedes, p. 227-248.

Cavalcanti, L. S. Concepções teórico-metodológicas da Geografia escolar no mundo contemporâneo e abordagens no ensino. In: Santos, L. L. C. P. et al. (Org.). (2010). Convergências e tensões no campo da formação e do trabalho docente. Belo Horizonte: Autêntica, p. 368-391.

Fonseca, S. G.; Borges, V. J.; Silva Jr., A. F. Ensinar Geografia e História - relações entre sujeitos, saberes e práticas. In: Fonseca, S. G. (Org.). (2007). Currículos, saberes e culturas escolares. Campinas: Alínea.

Goodson, I. F. Dar voz ao professor: as histórias de vida dos professores e o seu desenvolvimento profissional. In: Nóvoa, A. (Org.). (1995). Vidas de professores. Porto: Porto Editora, p. 63-78.

Guedes, P. C.; Souza, J. M. Não apenas o texto, mas o diálogo em língua escrita é o conteúdo da aula de português. In: Neves, I. C. B. et al. (Orgs.). (1999). Ler e escrever-compromisso de todas as áreas. Porto Alegre: UFRGS, p. 135-156.

Hernandéz, R. M. T. La autobiografia - forma de escritura de la vida para el conocimiento de si. In: Vicentini, P. P.; Abrahão, M. H. M. B. (Orgs.). (2010). Sentidos, potencialidades e usos da (auto) biografia. São Paulo: Cultura Acadêmica, p. 49-66. 
Monteagudo, J. G. La autobiografia educativa: formación, investigación y profesionalidad reflexiva. In: Moraes, D. Z.; Lugli, R. S. G. (Orgs.). (2010). Docência, pesquisa e aprendizagem: (auto) biografias como espaços de formação/investigação. São Paulo: Cultura Acadêmica, p. 69-85.

Nóvoa, A. Os professores e suas histórias de vida. In: Nóvoa, A. (Org.). (1995). Vidas de professores. Porto: Porto Editora.

Pimenta, S. G. A. Didática como mediação na construção da identidade do professor - uma experiência de ensino e pesquisa na licenciatura. In: André, M.; Oliveira, M. R. (Orgs.). (1997). Alternativas do ensino de didática. Campinas: Papirus.

Silva, A. P.; Barros, C. R.; Nogueira, M. L. M.; Barros, V.A . V. A. (2007). Conte-me sua história: reflexões sobre o método de história de vida. Revista Mosaico: estudos em psicologia, I (1), Belo Horizonte: UFMG. <www.fafich.ufmg.br/mosaico>. Acesso em: 26 set. 2011.

Tardif, M. (2010). Saberes docentes e formação profissional. Petrópolis: Vozes.

Artículo recibido 20 - 09 - 11. Aprobado 25 - $11-11$. 